Journal of Translation and Language Studies

jtls.sabapub.com
J Trans \& Lang Stud

$1(1): 67-77$

\title{
Another look at Syntactic Analysis of Hausa Verbs from Wallace Chafe's Semantic Structure Form Perspective
}

\author{
Ahmed Mohammed Bedu ${ }^{1, *}$ \\ ${ }^{1}$ Department of Language and Linguistics, University of Maiduguri \\ Received: 03.10.2020 • • Accepted/Published Online: 15.11.2020 • Final Version: 15.11.2020
}

\begin{abstract}
For several decades, linguists concluded that semantic structure is the area in which the well-formedness of the sentence is determined in all-natural languages. Over these years, the issue of semantic structure in syntactic analysis of Hausa verbs takes a back-seat in the Hausa language research despite the centrality of the verb as category that determines the organization of the rest categories of the sentence. The present paper employs Wallace Chafe's semantic structure theory to analyze Hausa sentences that were generated from the Parsonian seven grades of Hausa verbs to justify their structural consideration within semantic structure theory which specifies verb semantically in term of their semantic units that include states, processes and actions. The findings of paper indicate that the semantic formation rules govern the configuration of the basic semantic element in well-formed 'semantic structure' underlying the sentence of the language in which verbs dictate the selection of accompanying nouns and of the relations which such nouns bear to verbs..
\end{abstract}

Keywords: semantic structure, states, processes, actions, ambients

\section{Introduction}

For several decades, various linguistic researches have shown a consensus of linguists that semantic structure is the area in which the well-formedness of the sentence is determined in all natural languages (Katz and Fodor, 1963; Katz and Postal, 1964). These researches have equally demonstrated the ubiquitous of the semantic structure in the theory of syntax (Lakoff, 1970). The central claims of semantic structure theory focus on the centrality of the verb as the grammatical category that determines the main features in the organization of other categories in the sentence construction (Chomsky, 1955). Despite these claims, the issue of semantic structure in syntactic analysis of Hausa verbs takes a back-seat in the Hausa language studies. Though, it is a known issue that placing semantics outside grammar is harmful to linguistics (Chafe, 1970).

There is a substantial amount of literature devoted to the investigation of the syntactic configurations of Hausa sentence constructions (Bagari, 1979; Tuller, 1986; Munkaila, 1990, and Yusuf, 1991). In all these scholarly works, Hausaists like all other linguists agree that verbs and their accompanying nouns may be specified semantically in term of the semantic unit of various kinds. But the popular linguistic research on Hausa verbs by

\footnotetext{
* Corresponding Author: ahmedbedu@gmail.com
} 
Parsons $(1960,1962,1970-72$, and 1975) that is influencing the syntactic analysis of Hausa sentence constructions, for over three decades, is not adequate in explaining the centrality of verbs, being the syntactic component that determines the main features of the organization of the rest of the sentence especially the semantic role associated with the selection of agent (agt) and patient (pat) in the sentence constructions.

In view of this, the present paper intends to only revisit Parsonian classification of Hausa verb and re-integrate it into the Chafe's (1970:11) theory of semantic structure that assumes "The total human conceptual universe is dichotomized into two major areas, that is, the area of a verb, which embraces states and events, and the area of noun which embraces things".

\section{Literature Review on Parsons' Classification of Hausa Verbs}

Parsons' (1960) Grade system posits seven morpho-syntactic and semantic classes of Hausa verbs, though the classification leaves out a number of verbs (Newman 1973 and Furniss 1981). According to Parsons (1960, 1962, 1971-72), there are seven verbal grades in Hausa language. These seven grades were divided into the basic (primary) and derived (secondary) verbs and each grade characterized by a tonal pattern, a verbal ending, and some semantic and syntactic correlates.

From syntactic organization, the verb is assumed as A-form when no object following; it is a B-form when the verb is followed by a pronominal object, and if a verb is followed by a nominal object, such verb is a C-form, and a $\mathrm{D}$-form of the verb is followed by a dative object. The seven grades of Hausa verbs, tone patterns, vowels ending and their various forms are given below:

Table 1. The Hausa Verb Grade Systems and Forms. (Disyllabic Verbs)

\begin{tabular}{|c|c|c|c|c|c|c|c|}
\hline & \multicolumn{3}{|c|}{ Basic (Primary) } & \multicolumn{4}{|c|}{ Derived (Secondary) } \\
\hline & Grade 1 & Grade 2 & Grade 3 & Grade 4 & Grade 5 & $\begin{array}{l}\text { Grade } \\
6\end{array}$ & Grade 7 \\
\hline $\begin{array}{l}\text { A-form } \\
\text { (Before } \varnothing \\
\text { object) }\end{array}$ & $\mathrm{HL}-\mathrm{aa}$ & LH -aa & LH -a & HL -ee & $\mathrm{HH}-\mathrm{ar} / \mathrm{as}$ & $\mathrm{HH}-\mathrm{OO}$ & $\mathrm{LH}-\mathrm{u}$ \\
\hline $\begin{array}{l}\text { B-form } \\
\text { (Before } \\
\text { pronominal } \\
\text { accusative) }\end{array}$ & $\mathrm{HL}$-aa & LH -ee & & $\mathrm{HL}-\mathrm{ee}$ & $\mathrm{HH}-\operatorname{ar}$ (dà) & $\mathrm{HH}-\mathrm{OO}$ & \\
\hline $\begin{array}{l}\text { C-form } \\
\text { (Before } \\
\text { nominal } \\
\text { accusative) }\end{array}$ & $\mathrm{HL}-\mathrm{a}$ & LH $-\mathrm{i}$ & & HL-ee/e & HH-ar(dà) & $\mathrm{HH}-\mathrm{Oo}$ & \\
\hline $\begin{array}{l}\text { D-form } \\
\text { (Before } \\
\text { dative } \\
\text { object) }\end{array}$ & $\mathrm{HL}$-aa & $\mathrm{HL}-\mathrm{aa}$ & $\mathrm{LH}-\mathrm{a}$ & $\mathrm{HL}-\mathrm{ee}$ & HH-ar(dà) & $\mathrm{HH}-\mathrm{Oo}$ & $\mathrm{LH}-\mathrm{u}$ \\
\hline
\end{tabular}


As for the syntactic properties of the verb grades illustrated in the table (1) above, gr1, gr4, gr5, and gr6 contain both transitive and intransitive verbs. Grade 2 is entirely transitive, while gr3 and gr7 are all intransitive. The valence in Parsonian analysis of Hausa verbs which has a basis on the presence or absence of an object in the sentence structure does not seem to be adequate because the issue of the subject noun in the sentence construction is totally skipped out in the classification despite the fact that subject noun is a syntactic argument controlled by a predicate. The notion 'valency pattern' in syntax counts for all arguments in the sentence construction including the subject which in transformational grammar are known as Noun Phrase (NP) agent that Parsonian classification failed to define its role in all the verb grade system.

Semantically, verb, as the head of the predicate of the sentence structure, is supposed to be an interesting phenomenon due to its complex nature in Hausa language, but P. W. Parsons does not elaborate on this point for all the grades especially the relations between verb to subject and object nouns apart from structural semantic properties of verbs. The semantic issue in Parsons analysis of Hausa verb is limited to the categorization of these verbs in which Grades 1,2, and 3 are considered to be basic from which the secondary grades that include grade 4 and 5 or the tertiary grades (grade 6 and 7) are derived. In addition to this, Parsons (1962:250) fails to provide the multifunctional and semantic role of Hausa verbs in the syntactic constructions apart from explaining the exact meaning that the analysis assigns to the individual verbs based on lexical semantic perspective. This can be seen in table (2) below:

Table 2. Meaning and Transitivity of Hausa Verb Grade

\begin{tabular}{|c|c|c|c|c|}
\hline \multirow{4}{*}{$\begin{array}{l}\text { Basic Grade } \\
\text { (Primary) }\end{array}$} & & $\begin{array}{l}\text { Transitivity } \\
\text { value }\end{array}$ & $\begin{array}{l}\text { Meaning } \\
\text { label }\end{array}$ & Example \\
\hline & Grade 1 & $\begin{array}{l}\text { Transitive and } \\
\text { intransitive }\end{array}$ & Basic & $\begin{array}{l}\text { Dafàa 'cook' } \\
\text { nadàa 'turban' }\end{array}$ \\
\hline & Grade 2 & Transitive & Basic & $\begin{array}{l}\text { Aikkaa 'send' } \\
\text { Yànkaa 'cut off' }\end{array}$ \\
\hline & Grade 3 & Intransitive & Basic & $\begin{array}{l}\text { Shìga 'enter' } \\
\text { Cìka 'died' }\end{array}$ \\
\hline \multirow{4}{*}{$\begin{array}{l}\text { Derived } \\
\text { Grade } \\
\text { (Secondary) }\end{array}$} & Grade 4 & $\begin{array}{l}\text { Transitive and } \\
\text { intransitive }\end{array}$ & Totality & $\begin{array}{l}\text { Sayèe 'buy up' } \\
\text { Zubèe 'leak away' }\end{array}$ \\
\hline & Grade 5 & Transitive & Causative & $\begin{array}{l}\text { Durkusar (dà) 'bring to } \\
\text { knee' } \\
\text { Jeefar (dà) 'throw away' }\end{array}$ \\
\hline & Grade 6 & $\begin{array}{l}\text { Transitive and } \\
\text { intransitive }\end{array}$ & Ventive & $\begin{array}{l}\text { daukoo 'pick up and come' } \\
\text { Daawoo 'come back' }\end{array}$ \\
\hline & Grade 7 & Intransitive & Completive & Kàràntu 'well read' \\
\hline
\end{tabular}


The table (2) above illustrates that the various semantic properties of the verbs in the parson's analysis are semantic connotations ascribe to the individual verbs in term of their morphological nature not syntax which adequately describes and explains the selection of agent (agt) or patient (pat) by the verbs of the sentence as postulated by semantic structure theory.

\section{Theoretical Framework}

The theoretical framework of the semantic structure is operating through what Chafe dubs as semantic configurations in which meanings are assembled. In semantic configurations, the post-semantic processes yield a series of post-semantic representation which can lead to surface structure. For one to reach to phonetic structure, the surface structure can be subjected to several processes that include symbolization which converts the still semantically oriented surface structure into an underlying phonological structure. After undergoing a series of phonological processes, the surface structure will then appear in its phonetic form as summarized in the semantic structure framework in the following schema:

Post-semantic processes Symbolization Phonological processes

Semantic structure $\rightarrow \longrightarrow$ Surface structure $\rightarrow-. \rightarrow$ Underlying phonological structure $\rightarrow \rightarrow$ Phonetic structure

Figure 1. Semantic structure schema

The figure (1) above depicts that the whole matter in sentence construction is a semantic structure in which configurations of meanings are to be found. Through post-semantic processes, which are similar to transformation in Transformation Generative Grammar (TGG) of Chomsky, the configurations are transformed into a series of post-semantic representations which eventually lead to a surface structure. In order to reach the phonetic structure, the surface structure has yet to be subjected to be several processes. This includes the symbolization processes which convert the still semantically oriented surface structure into its underlying phonological structure. After undergoing a series of phonological processes, the surface structure will then appear in its phonetic form ${ }^{1}$.

In the semantic structure framework, the verb is assumed to be central and the noun is peripheral because the verb in every language is always present semantically. Verb determines what rest of the sentence will be like; in particular, that it determines what nouns will accompany it, what the relation of these nouns to it will be, and how these nouns will be semantically specified. Consider the following structure in (1) below:

1. The man laughed

The verb laugh in the above sentence construction as an action dictates that it be accompanied by a noun, that the noun is related to it as an agent, and that the noun is specified as animate, perhaps also as a human. The correctness of this view is suggested by such facts as the following. If we are confronted with a surface structure such as in (2) below:

2. The chair laughed ${ }^{1}$ The direction of the arrow in the schema of the framework indicates that language is a process that converts
meaning into sound, not sound into meaning. 
When one forced to give a meaning of some kind, what he will do is to interpret chair as if it were abnormally animate as dictated by the verb. What we do not do is to interpret laugh in an abnormal way as if it were a different kind of activity, performed by inanimate object. This suggests that the verb is central to dictate the semantic structure of sentence construction in every language.

Another interesting claim on the centrality of the verb in the sentence structure is the issue of inflectional added to the verb in the semantic structure level as you can see in (3) below:

\section{The men laughed}

From structure (3) above, the fundamental question is that is inflectional -ed added to the verb or to the entire sentence? Is the presence of the semantic unit past means that the laughing took place in the past that is past applied to laugh or that the men's laugh took place in the past that is past applied to the configuration of laugh with men? I believe that question has no significance that any unit like past which added semantically to a verb is added simultaneously to the entire sentence which built around that verb in the same way that anything that happens to the sun affects the entire solar system.

In contrast, we may note that agent 'men' in structure (3) is plural unlike in the structure (1). Such inflectional is relevant only to that noun; it is not a meaning that extends over the sentence as a whole. In this sense, a noun is like a planet whose internal modification affects it alone, and not the solar system as a whole.

Having discussed the centrality of the verb in the sentence construction and peripheral nature of noun from a semantic structure perspective, let us now take a cursory look at verb classification within the framework of semantic structure.

\subsection{Classification of Verb from Semantic Structure Paradigm}

According to Chafe (1970), the term sentence provides a convenient way in which a verb dictates its accompanying nouns. The sentence as an independent structural entity has a starting point of its generation and the verb is all the starting point we need. Typically we have a sentence with a verb alone as in command otherwise known as imperative structure as in "come" or "go". Similarly, we can have a sentence with verb accompanied by one or more nouns, or a configuration of this kind to which one or more coordinate or subordinate verbs have been added to form a complex structure.

From a semantic structure perspective, the verb in all types of sentence structures can be categorized into states, processes and actions. Consider the following structures in (4-7):

4. a. the wood is dry

b. the rope is tight

c. the dish is broken

d. the elephant is dead

5. a. the wood dried

b. the rope tightened

c. the dish broke

d. the elephant died 
6. a. Michael ran

b. the man laughed

c. Harriet sang

d. the tiger pounced

7. a. Michael dried the wood

b. the man tightened the rope

c. Harriet broken the dish

d. the tiger killed the elephant

(adopted from Chafe 1970:96)

In structure (4) the nouns (wood, rope, dish, and elephant) are said to be in a state or condition (dry, tight, broken, dead). The remaining sentence in (5), (6) and (7) contained verbs which are not specified as states. As a rule of semantic structure, nonstates verb can be distinguished from states by the fact that they answer the question 'what happen?, what's happening and so on. A nonstate is a "happening," an event as in:

8. What happen?
a. The wood dried
b. The men laughed
c. Harriet broken the dish (but not for example)
d. *The wood was dry ${ }^{2}$

The structures in (8) above suggest that nonstate verbs can be regarded as processes and actions as illustrated in the structures in (5), (6) and (7). But these nonstates are not all of the same kind. In structure (5) for instance, the verbs are processes, where the noun is said to have changed its state or condition. It seems valid to dub the noun in (5) as a patient of the verb. While the verbs in (6) are of a different of sort, they have nothing to do with either a state or a change of state instead they express an activity of action, something which someone does.

A rule of thumbs which can help us to distinguish action from the process is that an action sentence will answer what did $\mathrm{N}$ do?, where $\mathrm{N}$ is some noun:

9. What did Harriet do?

a. She sang (but not for example)

b. * She died

Conversely, it is often the case that a simple process sentence will answer the question 'What happened to N?', to which a simple action is not an appropriate answer. Consider the structure in (10) below:

10. What happened to Harriet?
a. She died (but not)
b. * She sang

\footnotetext{
${ }^{2}$ Various other rough tests can be applied to distinguished verbs which are nonstates from states e.g

a. The wood is drying

b. The men are laughing

c. Harriet is breaking the dish (but not)

d. *The wood is being dry
} 
However, the structures in (7) appear that the verb in these sentences is simultaneously, both a process and an action. As a process, it involves a change in the condition of a noun, its patient. As an action it expresses what someone, its agent, does. The agent is still someone who does something to something as the patient of the verb. In this sense, the verbs in (7) are both processes and action as they can be identified by answering the following two questions in (11) and (12):

11. What did Harriet do?

a. She broke the dish

12. What happened to the dish

a. Harriet broke it

In summary, the verb can be specified as state or nonstate. To indicate that a verb may or may not be a state, a rule of the following form can be used:

13. $\vee \vee \cdots>>$ state

The fact that the arrow in (13) has a broken shaft means that its application is optional. This was explained in our explanation of the structure (4-7) above as summarized in figure (3) below:

Table 3. Verb and its types form semantic structure perspective

\begin{tabular}{|l|l|l|l|l|}
\hline $\begin{array}{l}\text { Structure } \\
\text { (in examples) }\end{array}$ & 4 & 5 & 6 & 7 \\
\hline Type of verb & .State & Process & Action & Process Action \\
\hline
\end{tabular}

These possibilities can therefore be captured in the following rule in (14):

14. $\mathrm{V}$

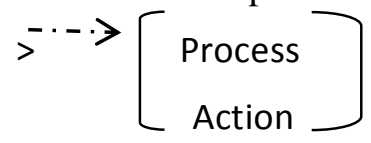

-State

In the rule in (14), the parentheses indicate an inclusive disjunction that is when there is presence of a nonstate state (-state) verb in the sentence, the verb can either be process or action or both. Though these four types of the verb can be realized in the sentence structure when the verb is accompanied by a patient and/or agent noun, it might be well to consider the possibility that no noun at all need is present in some sentences as illustrated below:

15. a. it's hot
b. it's late
c. it's Tuesday

The meaning of sentences in (15a-c) seems to involve nothing but a predication, in which there is no 'thing' of which the predication is made and the pronoun 'it' is a surface element only which need not reflect anything at all in the semantic structure. However, the verbs in the above structures apparently specified as a state but these sentences do not answer the question 'what's happening?' as earlier proposed nor can they be made progressive as in 
*it's being hot. In cases such as these, the state verb with such surface element can be specified as ambient.

In addition, we may also consider the following sentence in (16) below:

16. a. it's raining

b. it's snowing

Here too the above structures contain surface element 'it' that reflects nothing in the semantic structure. The sentences evidently do not express states for they answer the question 'what's happening?' Furthermore, they seem to express actions rather than processes for they answer the question 'what's it doing?', where the 'it' in the question does not reflect any item in the semantic structure either, though they express actions but without an assigned agent.

In this regard, the verb is ambient when it involves event without reference to particular thing within the environment. The framework adds another rule to existing ones that were earlier illustrated in this paper.

17. $\vee \quad-\cdot \rightarrow$ ambient

- process

In the rule (17), a verb which is not specified as a process may be optionally as ambient. Having looked at these developments, verbs in sentence construction can be specified in the following six ways as illustrated in the set of sentence indicated by their example numbers in this paper:

Table (4) Verb and its types form semantic structure perspective

\begin{tabular}{|l|l|l|l|l|l|l|}
\hline $\begin{array}{l}\text { Structure } \\
\text { (in examples) }\end{array}$ & 4 & 5 & 6 & 7 & 15 & 16 \\
\hline Type of verb & State & Process & Action & $\begin{array}{l}\text { Process } \\
\text { Action }\end{array}$ & $\begin{array}{l}\text { State } \\
\text { Ambient }\end{array}$ & $\begin{array}{l}\text { Action } \\
\text { Ambient }\end{array}$ \\
\hline
\end{tabular}

Having identified the types of verbs from semantic structure framework, the paper is now in a position to discuss how each of these six kinds of verb dictates the presence-absence of its accompanying nouns, as well as the semantic relations in term of patient and agent which such nouns bear to each verb in Hausa language in the Parsonian analysis of the verbal system of the language.

\section{Data Analysis ${ }^{3}$}

Since the concern of this paper is the centrality of the verb in Hausa sentence structure, the study will begin with grade 7 verb which Parson (1972) explains that its semantic values indicate completive of action as you can see in the following structure:

18. Audugaa taa sàyu 'the cotton has been well bought'

\footnotetext{
${ }^{3}$ What this paper is trying to present here is the semantic analysis of Hausa verbs and how they are brought up into surface structure. The paper restricts itself only to semantic structure and post-semantic processes leaving out the symbolization and phonological processes that convert the surface structure into its phonetic form (for details of the theoretical of semantic structure see Chafe, 1970)
} 
19. Riigaa taa dinku 'a shirt is well sewed'

From the structure in (18) and (19), the grade 7 verb has the unique characteristic of 'process' in the case of (18) and state in (19) and these types of the verb always require the accompaniment of a patient noun provided that it is not specified as ambient. In this sense, grade 7 verbs of Hausa language can be represented in semantic structure rule as in (20) below:

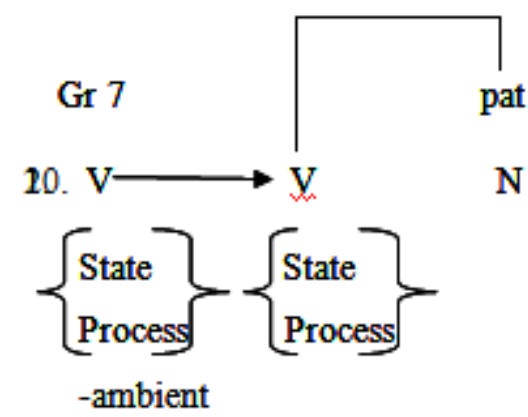

In the rule in (20), the 'pat' stands for patient noun which justifies that all Hausa structures that contain grade 7 verbs can be considered as medio- passive structure in the sense of Munkaila (1990) since the patient is in the position of subject in a normal deep structure sentence. Unlike grade 7, the grade 3 of Hausa verbs are typically processed that are accompanying with the only agent as you can see in the following structure in (21):

1. Amiinà taa cìka 'Amina died'

The above structure suggests that grade 3 verbs of Hausa language being semantically intransitive accommodate only agent nouns and this can also be represented in the schema of the semantic structure as in (22) below:

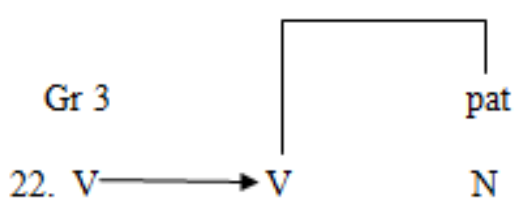

Process

The grade 1,2, 4, 5 and 6 verbs are semantically both process and action and their resulting configurations allow patient and agent nouns co-occur with a verb in the syntactic constructions. Consider the following structures in (23):

23. a. Auduu yaa rubùuta wàsiikàa 'Audu wrote a letter' (Gr 1.)

b. Kootu taa tùhùmi bàraawòo 'Court has prosecuted a theft' (Gr. 2)

c. Bàlaa yaa tumbùkee dòoyaa 'Bala has uprooted the yam' (Gr. 4)

d. Sheehù yaa durkusar da su 'Shehu has caused to bring them to their knees' (Gr. 5)

e. Maalàm yana kwaatsoo ruuwaa 'Malam poured water toward us' (Gr. 6) 
From a careful observation, the verbs in the configuration in (23 a-c) are semantically either actions or processes. However, apart from form $\mathrm{B}$ and $\mathrm{C}$ of grade 2 verb, all these verbs can be nominalized when preceded by a general or relative continuous of Hausa tense without losing their phonological, morphological and syntactic shape and do still select their noun agents and patients as you illustrated in (24) below:

24. a. Auduu yana rubùuta wàsiikàa (Gr 1.)

b. Kootu tana tùhùmaa/ *tùhùmi ta /(Gàraawòo) $\left(\right.$ Gr. 2) ${ }^{4}$

c. Bàlaa yana tumbùkee dòoyaa (Gr. 4)

d. Sheehù yana durkusar da su

e. Maalàm yana kwaatsoo ruuwaa

Despite the nominalization of the verb, the resulting configurations in (24) illustrate that all verbs are still retained their status of transitivity that cannot without an accompanying patient noun. This further suggests that verb and patient relation in these grades is more internal than the agent. In this regard, the Hausa verbs with characteristics of action and process can schematically be represented in (25) below:

25.

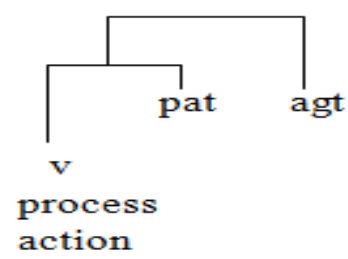

The schema in (25) above indicates that the action verb that at the same time, a process, can take both agent and patient in its syntactic configuration and this development confirms the centrality of the verb in determining the presence of accompanying nouns in the sentence structure.

On the state verbs and action verbs that contain ambient in Hausa language, you can find out that such sentence structures are in subjunctive tenses in the language. For instance an yi ruuwaa 'it has rained' or ana ruuwa 'it's raining.

\section{Conclusion}

In the above discussion, we saw how a verb may be specified in terms of semantic units like state, process, action and ambient. It is evident in this paper that the primary role of the verbs in the syntactic configuration in every language is not limited to denote action but it includes the role in the selection of accompanying noun and of the relations which such noun bear to verbs. These accompanying nouns must always obey the selection manner and characteristic of the verb as the highest element in the hierarchical constituent that is known as the predicate in the traditional grammar.

${ }^{4}$ The instance in which grade 2 verb cannot be nominalized in form B and C suggests the partitive nature of the verb 


\section{References}

[1] Bagari, Dauda Muhammad. 1976. Subordinate adverbial clause in Hausa. Ph.D. Dissertation, University of California Los Angeles.

[2] Chafe, W. L . 1970. Meaning and the strucrure of Language. Chicago: University of Chicago Press,

[3] Chomsky, N, 1955. Semantic Consideration in Grammar Georgetown University Monograph Series on Language and Linguistics. Georgetown University Press. Washintong D.C.

[4] Furniss, Graham L. 1981. Hausa disyllabic verbs: Comments on base forms and extensions. Studies in African Linguistics 12.97-129.

[5] Katz, J. J. and J. A. Fordor. 1963. The structure of a semantic theory, language, vol.39: 1-49

[6] Katz, J. J. and P. M. Postal 1964. An integrated Theory of linguistic descriptions. Massachusette The MIT Press

[7] Lakoff. G. 1970. Irregularality in Syntax. New York: Holt. Rinehart and Winston, Inc

[8] Munkaila, Muhammad M. 1990. Indirect object constructions in Hausa. Ph.D. dissertation, School of Oriental and African Studies, University of London.

[9] Newman, Paul. 1973. Grades, vowel-tone classes and extensions in the Hausa verbal system. Studies in African Linguistics 4.297-346.

[10] Parsons, F.W. 1960. The Verbal system in Hausa: forms, function and grades. Afrika und Übersee 44:1.1-36.

[11] Parsons, F.W. 1962. Further observations on the "causative" grade of the verb in Hausa. Journal of African Languages 1:3.253-272.

[12] Parsons, F.W. 1971-72. Suppletion and neutralization in the verbal system of Hausa. Afrika und Übersee 55.49-97, 188-208.

[13] Parsons, F.W. 1975. Hausa and Chadic. Hamito-semitica, ed. by James \& Theodora Bynon, 421455. The Hague: Mouton.

[14] Tuller, L. (1986) Bijective Relations in Universal grammar and the Syntax of Hausa Ph. D. Thesis, University of California Los Angeles.

[15] Yusuf, M. A. (1991). Aspect of Morphosyntax of Functional Categories in Hausa. Ph. D. Dissertation, University of Essex.

[16] Altam, S. (2020). Influence of social media on EFL Yemeni learners in Indian Universities during Covid-19 Pandemic. Linguistics and Culture Review, 4(1), 35-47. https://doi.org/10.37028/lingcure.v4n1.19 